\title{
EL FRACASO DEL PROYECTO DE LEY CONSTITUCIONAL «DE PROTECCIÓN DE LA NACIÓN»PARA INCLUIR EN LA CONSTITUCIÓN FRANCESA EL ESTADO DE URGENCIA Y LA PRIVACIÓN DE LA NACIONALIDAD ${ }^{1}$
}

\author{
STEPHANE PIERRE-CAPS ${ }^{2}$ \\ Catedrático de Derecho Público \\ Universidad de Lorraine
}

\section{SUMARIO}

I. La constitucionalización del estado de urgencia. II. La constitucionalización de la privación de la nacionalidad.

El 16 de noviembre de 2015, tres días después de los atentados terroristas de París, el presidente de la República se dirigió solemnemente a los parlamentarios reunidos en sesión conjunta ${ }^{3}$ en Versalles ${ }^{4}$. Estimando que «debemos hacer evolucionar nuestra Constitución para permitir a los poderes públicos reaccionar, conforme al Estado de Derecho, contra el terrorismo de guerra», el jefe del Estado propuso entonces una revisión de la Constitución: «se trata de poder disponer de una

1 Traducción de E. Gilbaja Cabrero, Profesora de Derecho Constitucional de la Universidad de Valladolid.

2 Director del Instituto de Investigaciones sobre la evolución de la Nación y del Estado (Institut de Recherches sur l'evolution de la Nation et de l'Etat, Irenee).

3 En el Derecho parlamentario francés se habla de Parlamento reunido o convocado en Congreso (Parlement réuni/convoqué en Congrès) para referirse a lo que en España se denomina «sesión conjunta» de ambas Cámaras de las Cortes Generales; en el caso francés, la Asamblea nacional y el Senado (nota de la traductora).

4 Tras la ley constitucional de 23 de julio de 2008, se reconoce al jefe del Estado el derecho a «tomar la palabra ante el Parlamento reunido a estos efectos en Congreso. Su declaración podrá dar lugar, fuera de su presencia, a un debate que no será objeto de ninguna votación» (artículo 18, párrafo 2 de la Constitución) (versión en castellano de la Constitución francesa publicada en bttp://www.justice.gouv.fr/art_pix/constitution-espagnol_juillet2008.pdf). 
herramienta apropiada para fundamentar la toma de medidas excepcionales de una determinada duración, sin recurrir al estado de sitio y sin comprometer el ejercicio de las libertades públicas. Esta revisión de la Constitución debe acompañarse de otras medidas. Se trata de la privación de la nacionalidad. La privación de la nacionalidad no debe tener como resultado convertir a nadie en apátrida, pero debemos poder privar de su nacionalidad francesa a un individuo condenado por un atentado contra los intereses fundamentales de la nación o un acto de terrorismo, incluso si ha nacido francés, digo bien «incluso si ha nacido francés» cuando disponga de otra nacionalidad». Esta proposición de constitucionalización del estado de urgencia y de la privación de la nacionalidad francesa tomó inmediatamente la forma de proyecto de ley constitucional «de protección de la nación» el 23 de diciembre de 2015, y dio lugar a un intenso debate político y constitucional.

En lo que se refiere en particular a la constitucionalización del estado de urgencia, se ve planteada de nuevo la tan antigua cuestión de la relación entre la situación de excepción y el Derecho.

Frente a Carl Schmitt, para quien «es soberano quien decide sobre la situación excepcional» ${ }^{5}$, Herman Heller objeta que «no hay «situación normal» $\mathrm{y}$ «situación de excepción» sin una norma que permita distinguirlas y ésta debe aplicarse aún en la situación de excepción $»^{6}$. En otras palabras, «solamente por el elemento normativo una situación de dominación momentánea y completamente imprevisible puede normalizarse convirtiéndose en una situación de continuidad y de previsibilidad, es decir, vinculada a una Constitución perdurable más allá del momento» ${ }^{7}$.

Esta «normalización» de la situación de excepción por el recurso a la normatividad está en el núcleo de la cuestión de su constitucionalización, tal y como se encuentra planteada en Francia a raíz de los atentados del 13 de noviembre de 2015: el Derecho, instrumento de la estabilidad y de la normalidad social, ¿puede tomar el control de la situación y de qué manera? Más ampliamente, la misma determina la relación dialéctica que sustenta las legislaciones nacionales de seguridad confrontadas de este modo con las libertades fundamentales. Aquélla determina también el papel y la acción jurisdiccionales, sean o no éstos tributarios del marco predefinido por el constituyente y por el legislador nacional.

Igualmente vivo fue el debate relativo a la cuestión de la privación de la nacionalidad a las personas nacidas francesas. Este debate fue también fuente de confusión en cuanto a lo que supone hoy en día la noción de nacionalidad. Mientras que algunos ponen el acento sobre el estatuto y los derechos ligados a la nacionalidad, hasta el punto de considerarla en adelante como un derecho natural del hombre, otros recuerdan que «la nacionalidad es la institución jurídica de la base humana del Estado» y en consecuencia «es el Estado soberano y solamente

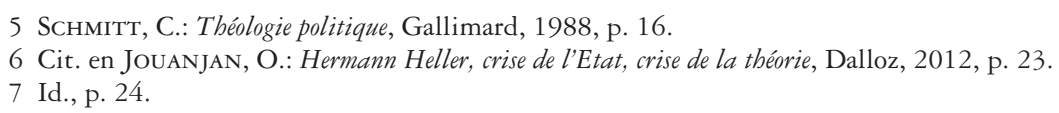


él quien confiere y por tanto determina su nacionalidad» ${ }^{8}$. Éstos son precisamente los dos puntos de vista diferentes sobre la nacionalidad que estuvieron en el origen del desacuerdo irreductible entre las dos cámaras parlamentarias, la Asamblea nacional y el Senado, en el momento de la discusión del proyecto de ley constitucional, lo que condujo finalmente al presidente de la República a renunciar a esta revisión constitucional en un comunicado del 30 de marzo de 2016.

El proyecto de ley constitucional «de protección de la nación» constaba así de dos partes: la constitucionalización del estado de urgencia, por un lado (1.), y la posibilidad de la privación de la nacionalidad a las personas nacidas francesas, por otro (2.) $)^{9}$.

\section{LA CONSTITUCIONALIZACIÓN DEL ESTADO DE URGENCIA}

Dos cuestiones se planteaban al respecto: el régimen jurídico del estado de urgencia, primero (A.), y la duración del estado de urgencia, después (B.).

\section{El régimen jurídico del estado de urgencia}

La noción de estado de urgencia apareció en el Derecho público francés con la ley n. ${ }^{\circ}$ 55-385 de 3 de abril de 1955 «relativa al estado de urgencia». Dicha

8 Borella, F.: «Nationalité et citoyenneté en droit français», Colas, D. (dir.): L'Etat de droit, Paris, PUF, 1987 , pp. 30 y 31.

9 Se recordará que el procedimiento de revisión de la Constitución, tal y como se prevé en el artículo 89, comprende tres fases. Al inicio, la de la iniciativa, que puede corresponder bien al presidente de la República a proposición del Primer ministro, bien a los propios parlamentarios. Siguiendo la terminología habitual en materia de iniciativa legislativa ordinaria, el texto de revisión toma el nombre de proyecto en el primer caso y de proposición en el segundo.

Se encuentra a continuación la fase de debate y votación, que se desarrolla en el seno de cada asamblea de forma separada, del mismo modo que una ley ordinaria, incluido lo relativo a los plazos de tramitación (artículo 89, párrafo 2). Con la gran diferencia, no obstante, de que la ida y vuelta entre las dos cámaras del Parlamento es aquí indefinida: cada asamblea tiene, por tanto, un derecho de veto absoluto en relación a la otra. Ambas deben obligatoriamente ponerse de acuerdo sobre un texto idéntico.

Finalmente, la tercera fase plantea el problema del referéndum y, sobre este punto, la redacción del artículo 89 no es muy afortunada: el texto parece indicar que, tras su aprobación por cada asamblea en términos idénticos, el proyecto de revisión debe someterse a referéndum. Sin embargo, el párrafo 3 del artículo 89 permite evitar el referéndum solamente para los proyectos de revisión. Pero cuando un texto ha sido aprobado por las dos asambleas en términos idénticos, la práctica hace que se le llame, en todo caso, proyecto. El referéndum puede entonces evitarse cuando el presidente de la República decide someter el texto de revisión al Parlamento convocado en sesión conjunta en Versalles. El texto de revisión deberá entonces aprobarse definitivamente por mayoría de tres quintos de los votos emitidos. Este procedimiento del Congreso puede justificarse por el objetivo de evitar referéndums menores y distinguir las revisiones constitucionales grandes de las pequeñas. Pero la práctica no ha confirmado esta preocupación, en la medida en que grandes revisiones constitucionales se han basado en la opinión del Congreso. El proyecto de ley constitucional «de protección de la nación» se debería haber aprobado también por el Parlamento en sesión conjunta (en Congrès).

UNED. Teoría y Realidad Constitucional, núm. 38, 2016, pp. 507-528 
ley fue aprobada en el contexto naciente de lo que aún no se llamaba la «guerra de Argelia». Tradujo el rechazo del Gobierno de la época, en una suerte de denegación, a calificar de «guerra» la crisis argelina que había comenzado el 1 de noviembre de 1954. Además de las implicaciones políticas de una calificación tal, ello habría conducido, en efecto, a los poderes públicos de la IV República a aplicar la única situación de excepción que conocía entonces el Derecho público francés, a saber: «el estado de sitio». "Heredero del Derecho marcial del Antiguo Régimen ${ }^{10}$, el estado de sitio se había constitucionalizado en $1954^{11}$. El estado de sitio es un estado de crisis donde los poderes de las autoridades militares se encuentran considerablemente ampliados. Nunca fue puesto en práctica durante la IV ni la V Repúblicas.

Por lo expuesto, la aparición del estado de urgencia «puede concebirse como una nueva generación de las técnicas de mantenimiento del orden ${ }^{12}$. Por otra parte, el régimen jurídico del estado de urgencia se distingue del del estado de sitio "por una extensión de los poderes de policía aún más importante que en el marco del estado de sitio, pero en esta ocasión en beneficio de las autoridades civiles y principalmente los prefectos» ${ }^{13}$. Comprende restricciones significativas de las libertades públicas (libertad de circulación, de reunión y de manifestación, extensión de los registros, requerimiento de personas y bienes). Aparece así, sin discusión, como «el más estricto de los regímenes de suspensión de derechos susceptibles de ponerse en práctica» ${ }^{14}$.

Sin embargo, los constituyentes de 1958 no se preocuparon, sin que se sepa el porqué, de incluir el estado de urgencia en el nuevo texto constitucional, a pesar de que incluso evocaron el estado de sitio en el artículo $36^{15}$. Pero los poderes públicos no deberían, por lo explicado, desinteresarse de dicha noción, puesto que la orden n. ${ }^{\circ} 60-372$ de 15 de abril de 1960, por la que se modifican determinadas disposiciones de la ley de $1955^{16}$, tuvo que ajustar el régimen jurídico del estado de urgencia al del estado de sitio tal como estaba previsto en el artículo 36

10 Rolin, F.: «L'état d'urgence», MAThieu, B. (dir.): 1958-2088 Cinquantième anniversaire de la Constitution française, Paris, Dalloz, 2008, p. 611.

11 Ley de 7 de diciembre de 1954, artículo 7 de la Constitución de 1946: «El estado de sitio se declara en las condiciones previstas por la ley». El estado de sitio se mencionaba anteriormente en el artículo 106 de la Constitución de 1848 .

12 Rolin, F.: «L'état d'urgence», art. cit., p. 612.

13 JaCQuinot, N.: «Le juge administratif et le juge constitutionnel face à l'état d'urgence», Mélanges Louis Favoreu, Dalloz, 2007, p. 731

14 Rolin, F.: art. cit., p. 612.

15 «El estado de sitio es declarado en Consejo de ministros. Su prórroga más allá de doce días sólo puede ser autorizada por el Parlamento».

16 Este texto se basaba en la ley n. ${ }^{\circ} 60-101$ de 4 de febrero de 1960 por la que se autoriza al Gobierno a tomar, en virtud del artículo 38 de la Constitución, ciertas medidas relativas al mantenimiento del orden, a la salvaguardia del Estado, a la pacificación y a la administración de Argelia. El artículo 38 de la Constitución habilita al Gobierno a aprobar leyes por medio de orden. Las órdenes son, pues, textos emitidos por el Gobierno en materias que normalmente son del ámbito de la ley como dispone el artículo 34 de la Constitución. 
de la Constitución, transfiriendo al poder gubernamental la competencia legislativa en cuanto a la declaración del estado de urgencia.

Se trataba sobre todo de fortalecer, bajo el imperio de la nueva Constitución, la preeminencia del poder gubernamental en cuanto a la apreciación de toda situación de excepción, lo que incluye los poderes de crisis del artículo 16, el estado de sitio y el estado de urgencia. Se verificó, por otra parte, cuando el presidente de la República recurrió al artículo 16, el 23 de abril de 1961, al cual vino a añadirse la declaración del estado de urgencia ${ }^{17}$ y, sobre todo, su prolongación hasta nueva orden por una decisión del jefe del Estado tomada en el marco del artículo 16, el 24 de abril de $1961^{18}$. Sin embargo, la prolongación del estado de urgencia más allá de 12 días es de la competencia exclusiva del Parlamento ${ }^{19}$. El presidente de la República, de este modo, se había apropiado de la duración de la situación de excepción, más allá incluso del fin de la aplicación del artículo 16, el 29 de septiembre de 1961. En efecto, una decisión presidencial del 29 de septiembre mantuvo el estado de urgencia hasta el 15 de julio de 1962, y después la orden n. ${ }^{\circ}$ 62-797 de 13 de julio de 1962 lo prorrogó hasta una fecha fijada por decreto, que debía ser como máximo el 31 de mayo de 1963. Pero la disolución de la Asamblea nacional el 9 de octubre de 1962 supuso el fin del estado de urgencia. Una actitud tal del poder gubernamental de entonces tiende a subrayar, por contraste y como lo escribió Frédéric Rolin, «en qué medida una regulación constitucional del estado de urgencia es imperiosa para protegerse contra el retorno de tales prácticas» ${ }^{20}$.

Posteriormente, la cuestión se volvió a plantear con ocasión de la aplicación del estado de urgencia en Nueva-Caledonia, en 1985. El Parlamento aprobó, los días 23 y 24 de enero de 1985, una ley prorrogando el estado de urgencia en Nueva-Caledonia ${ }^{21}$. Esta ley fue inmediatamente llevada ante el Consejo constitucional. Los recurrentes estimaban que, al no estar contenido en la Constitución, el estado de sitio no debería instaurarse por la ley, habida cuenta de las restricciones a las libertades públicas que comporta, las cuales deben estar previstas por el texto constitucional. En su decisión n. ${ }^{\circ} 187$ DC de 25 de enero de $1985^{22}$, el Consejo constitucional respondió que el legislador dispone de una competencia general para «operar la conciliación necesaria entre el respeto de las libertades y la salvaguardia del orden público sin el cual el ejercicio de las libertades no esta-

17 Decretos n. ${ }^{\circ} 61-395$ y 61-396 de 22 de abril de 1961.

18 En virtud del artículo 16, el presidente de la República dispone no solamente del conjunto de los poderes gubernamentales, sino también del poder legislativo.

19 Artículo 3 de la orden de 15 de abril de 1960, precitada.

20 Id., p. 615.

21 Anteriormente el artículo 119 de la ley n. ${ }^{\circ} 84-821$ de 6 de septiembre de 1984 sobre el estatuto del territorio de la Nueva-Caledonia había extendido el régimen del estado de urgencia al territorio de la Nueva-Caledonia. El Consejo constitucional se abstuvo de controlar esta disposición en su decisión n. ${ }^{\circ}$ 84-178 DC de 30 de agosto de 1984, Loi portant statut du territoire de la Nouvelle-Calédonie et dépendance, Rec., p. 69.

22 Rec., p. 43. 
ría asegurado» (considerando 3). Por ello, esta competencia no necesita estar expresamente prevista por la Constitución. De ahí resulta que el artículo 36 de la Constitución, si bien se refiere sólo al estado de sitio, no excluye sin embargo la posibilidad por parte del legislador de prever un régimen de estado de urgencia, como es el caso de la ley de 3 de abril de 1955 y que la Constitución de 1958 no deroga. A este respecto, el Consejo constitucional subrayó asimismo que la ley de 1955 se modificó bajo la vigencia de la nueva Constitución, absteniéndose de mencionar la orden precitada de 15 de abril de 1960.

No hay duda de que el Consejo constitucional dio muestra aquí de pusilanimidad guardándose de precisar el marco jurídico del estado de urgencia en relación con las libertades públicas. Ciertamente, esto debería llevar a un examen a fondo de la ley. Sin embargo, consideró que la ley sometida a su examen no era más que una "puesta en práctica» (considerando 10) de la de 1955 modificada por el artículo 119 de la ley de 6 de septiembre de 1984. Ahora bien, el Consejo constitucional, en los términos de la misma decisión, no acepta examinar, en virtud de su control a priori, la regularidad de una ley ya promulgada más que «con ocasión del examen de disposiciones legislativas que la modifican, la completan o afectan a su ámbito».

Pero, como escribió de forma expresiva Pascal Caille: «la referencia a una habilitación implícita de la Constitución se presenta menos como una deducción lógica e irrefutable que como la manifestación de la preocupación del juez constitucional de no censurar el recurso a una legislación de excepción en un momento en que la crisis estaba efectivamente abierta $»^{23}$. Esta autocontención del juez constitucional manifiesta, de hecho, una suerte de sumisión al poder gubernamental. Refleja la preocupación por no obstaculizar su acción en situación de excepción. Se acerca bastante a la concepción de Schmitt. David Dyzenhays remarcó también que «en circunstancias de urgencia presupuesta, ningún tribunal se interpondrá en el camino del ejecutivo, ni siquiera teniendo autoridad, formalmente al menos, para oponerse» ${ }^{24}$.

Es un hecho que el régimen legislativo del estado de urgencia ha escapado prácticamente a todo control de constitucionalidad, al menos en el marco del control a priori, a pesar de haberse aplicado en varias ocasiones: en 1985 en Nueva-Caledonia, en 2005 a propósito de los disturbios en los suburbios (ley n. ${ }^{\circ} 2005$ 1425 de 18 de noviembre de 2005 por la que se prorroga la aplicación de la ley de 3 de abril de 1955) y en 2015-2016 (ley n. ${ }^{\circ} 2015-1501$ de 20 de noviembre de 2015 por la que se prorroga la aplicación de la ley n. ${ }^{0} 55-385$ de 3 de abril de 1955 relativa al estado de urgencia y se refuerza la eficacia de sus disposiciones; ley n. ${ }^{\circ} 2016$ 162 de 19 de febrero de 2016 y ley n. ${ }^{\circ} 2016-629$ de 20 de mayo de 2016, por las

23 Caille, P.: «L'état d'urgence. La loi du 3 avril 1955 entre maturation et dénaturation», Revue du Droit public, n. ${ }^{\circ} 2-2007$, p. 349

24 Dyzenhaus, D.: «L'état d'exception», Troper, Michel y Chagnollaud, D. (dir.): Traité international de droit constitutionnel, T. II, Distribution des pouvoirs, p. 739. 
que se prorroga la aplicación de la ley de 3 de abril de 1955; y ley n. ${ }^{\circ} 2016-987$ de 21 de julio, por la que se prorroga la aplicación de la ley n. ${ }^{\circ}$ 55-385 de 3 de abril de 1955 relativa al estado de urgencia y se aprueban medidas de refuerzo de la lucha antiterrorista ${ }^{25}$ ). La ley de 20 de noviembre de 2015 modifica sensiblemente la ley de 1955: refuerza notablemente el régimen de los arrestos domiciliarios y de los registros y amplía el marco de la disolución de asociaciones. Por esta razón, se podría haber llevado ante el Consejo constitucional bajo el fundamento del artículo 61 de la Constitución. Por lo tanto, no son ocasiones lo que han faltado: los recurrentes potenciales, que son los parlamentarios en el marco del control a priori, no han querido someter las leyes concernidas al Consejo constitucional, dejando así primar la excepción sobre el Derecho y desplegar todo su potencial.

Finalmente, a título de la cuestión prioritaria de constitucionalidad (question prioritaire de constitutionnalité o QPC), el Consejo constitucional conoció de la ley de 20 de noviembre de 2015: en una decisión de 22 de diciembre de 2015 ( ${ }^{\circ}$ 2015-527 QPC) determinó que el régimen del arresto domiciliario (artículo 6 de la ley) no comportaba privación de la libertad individual en el sentido del artículo 66 de la Constitución. Este control constitucional a posteriori no pone realmente en cuestión la subordinación del juez al poder gubernamental en situación de excepción, recordando de este modo el Consejo constitucional que la falta de competencia negativa del legislador solamente puede ser invocada sobre la base de una QPC en la medida en que aquélla «afecte por sí misma a un derecho o una libertad que la Constitución garantiza» (considerando 9). Fue necesario, no obstante, esperar a la resolución de 19 de febrero de 2016 (n. . 2016-536 QPC) para que el Consejo constitucional sancionase el hecho de copiar los datos informáticos con ocasión de un registro, asimilado de este modo a una incautación de datos sin autorización judicial (artículo 11 de la ley de 1955).

En estas condiciones, la inclusión del estado de urgencia en la Constitución, en los términos del proyecto de ley constitucional «de protección de la nación», aprobado por la Asamblea nacional en primera lectura, el 10 de febrero de $2016^{26}$,

25 El presidente de la República tenía intención de declarar el fin del estado de urgencia una vez terminados la Eurocopa y el Tour de Francia, pero el atentado terrorista producido en Niza el 14 de julio de 2016 derivó en la prórroga del estado de urgencia por 6 meses más, mediante la ley n. ${ }^{\circ} 2016-987$ de 21 de julio (nuevos datos añadidos por la traductora).

26 «A continuación del artículo 36 de la Constitución, se inserta un artículo 36-1 con la siguiente redacción:

"Art. 36-1. El estado de urgencia es decretado en Consejo de ministros, sobre todo o una parte del territorio de la República, sea en caso de peligro inminente resultante de ataques graves contra el orden público, sea en caso de acontecimientos que presenten, por su naturaleza y su gravedad, el carácter de catástrofe pública.

La ley fija las medidas de policía administrativa que las autoridades civiles pueden tomar para prevenir ese peligro o hacer frente a esos acontecimientos.

Durante el estado de urgencia, el Parlamento se reúne de pleno derecho.

La Asamblea nacional y el Senado son informados sin demora de las medidas tomadas por el Gobierno durante el estado de urgencia. Pueden requerir cualquier información complementaria en el marco del control 
y después por el Senado, mediando sustanciales modificaciones ${ }^{27}$, no tenía en sí mismo nada sorprendente: participaba de lo que David Dyzenhaus denomina la «Constitución de urgencia» por adaptación, lo cual es realmente paradójico, de la Constitución a la situación de excepción: «declarando el estado de excepción, el Gobierno debe reivindicar la autoridad de la Constitución legal para reaccionar fuera del Derecho (...). El Derecho debe por tanto utilizarse a fin de suspender su propia aplicación ${ }^{28}$, reflejando aquí la posición kelseniana según la cual el soberano debe siempre operar conforme al Derecho, puesto que él mismo está completamente conformado por el Derecho.

Por otra parte, la constitucionalización del estado de urgencia ya había sido sugerida por los Comités «Vedel» de 1993 y «Balladur» de $2007^{29}$, encargados entonces de proponer al jefe del Estado modificaciones de la Constitución. El primero indicaba: "por razones circunstanciales, la Constitución no menciona más que el estado de sitio en el artículo 36. Parece necesario, de aquí en adelante, regular el estado de urgencia imitando la configuración del estado de sitio incluyendo en la Constitución las reglas que ya figuran en la ley reguladora del estado de urgencia». Se sugirió de este modo elevar al nivel constitucional el régimen jurídico del estado de urgencia según lo previsto por la ley de 1955. Y el proyec-

y de la evaluación de esas medidas. Los reglamentos de las asambleas prevén las condiciones en las cuales el Parlamento controla la puesta en marcha del estado de urgencia.

La prórroga del estado de urgencia más allá de doce días sólo puede ser autorizada por la ley. Ésta fija la duración, que no puede exceder de cuatro meses. Esta prórroga puede ser renovada en las mismas condiciones"».

27 «A continuación del artículo 36 de la Constitución, se inserta un artículo 36-1 con la siguiente redacción:

“Art. 36-1. El estado de urgencia es decretado en Consejo de ministros, tras consulta a los presidentes de las asambleas, sobre todo o una parte del territorio nacional, en caso de peligro inminente resultante de ataques graves contra el orden público.

Las medidas de policía administrativa que pueden ser tomadas por las autoridades civiles para prevenir ese peligro son las estrictamente adecuadas, necesarias y proporcionadas.

No puede ir en contra de la competencia que la autoridad judicial, guardiana de la libertad individual, tiene atribuida por el artículo 66 («Nadie puede ser detenido arbitrariamente (...)»).

Durante el estado de urgencia, una proposición de ley o de resolución o un debate relativos al estado de urgencia se incluyen con prioridad en el orden del día a iniciativa de la conferencia de presidentes de cada asamblea o de al menos dos grupos parlamentarios durante la sesión ordinaria o una sesión extraordinaria o, llegado el caso, durante una reunión de pleno derecho del Parlamento.

La Asamblea nacional y el Senado son informados sin demora por el Gobierno de las medidas tomadas en virtud del estado de urgencia. A petición suya, el Gobierno les transmite toda información complementaria relativa a esas medidas.

La prórroga del estado de urgencia más allá de doce días sólo puede ser autorizada por la ley y en la estricta medida en que la situación lo exija. Ésta fija la duración, que no puede exceder de tres meses. Si las condiciones del estado de urgencia se continúan cumpliendo, esta prórroga puede renovarse del mismo modo. Puede ponerse fin al estado de urgencia por la ley o por decreto debatido en Consejo de ministros.

Una ley orgánica determina las condiciones de aplicación del presente artículo.” ”

28 Dyzenhaus, D.: «L'état d'exception», art. cit., p. 742.

29 Creados por decreto, estos «comités» estaban normalmente compuestos por altos magistrados y profesores de universidad. 
to de ley constitucional de 10 de marzo de 1993 relativa a la organización de los poderes públicos, que se quedó en proyecto, precisaba: «en tanto que autoriza precisamente serias restricciones a derechos fundamentales, el estado de urgencia entra en el dominio que la Constitución tiene vocación de regular». En cuanto al «Comité Balladur», constató igualmente que había lugar a poner en marcha los mecanismos del estado de sitio y del estado de urgencia, «modificando las disposiciones del artículo 36 de la Constitución de manera que el régimen de cada uno de esos estados de crisis sea definido por ley orgánica y la ratificación de su prórroga sea autorizada por el Parlamento en condiciones armonizadas». La razón que se dio para esta armonización de las disposiciones relativas a las situaciones de excepción se refería a «la diversidad de las amenazas potenciales que pesan sobre la seguridad nacional en la era del terrorismo globalizado». El «Comité Balladur» retomaba así la redacción a minima del artículo 36 de la Constitución, ya sugerida por el «Comité Vedel», en cuanto a la inclusión en la Constitución del estado de urgencia y, en particular, encomendaba a una ley orgánica la tarea de precisar el marco jurídico: «el estado de sitio y el estado de urgencia son decretados en Consejo de ministros. Su prórroga más allá de 12 días sólo puede ser autorizada por ley. Una ley orgánica definirá estos regímenes y precisará sus condiciones de aplicación». La remisión a una ley orgánica podría hacer suponer que el Consejo constitucional, situado a la fuerza ante el régimen jurídico y las condiciones de aplicación del estado de urgencia, no sé mojó en absoluto ${ }^{30}$.

No fue finalmente esta solución la que retuvo el proyecto de ley constitucional «de protección de la nación» tal y como fue aprobada en primera lectura por la Asamblea nacional el 10 de febrero de 2016. Éste, en efecto, procedía a la constitucionalización del artículo primero de la ley de 1955 en lo relativo a los motivos del recurso al estado de urgencia: «el estado de urgencia es decretado en Consejo de ministros, sobre todo o una parte del territorio de la República, sea en caso de peligro inminente resultante de ataques graves contra el orden público, sea en caso de acontecimientos que presenten, por su naturaleza y su gravedad, el carácter de catástrofe pública». Por otra parte, encomendaba a la ley ordinaria la tarea de fijar «las medidas de policía administrativa que las autoridades civiles pueden tomar para prevenir ese peligro o hacer frente a esos acontecimientos». Organizaba igualmente un control del Parlamento, que se reuniría de pleno derecho durante el periodo del estado de urgencia, sobre las medidas tomadas en el marco de éste. En su opinión emitida el 11 de diciembre de 2015 de forma previa a la aprobación del proyecto de ley constitucional en Consejo de ministros, el Consejo de Estado quiso recordar, en cuanto a la constitucionalización del estado de urgencia, que la ley de 1955 no había sido derogada por la Constitución, se-

30 Las leyes orgánicas, cuyo objeto es completar la Constitución, se someten obligatoriamente antes de su promulgación al Consejo constitucional, cuyo control no se refiere solamente a las formalidades procedimentales de aprobación, sino también sobre su conformidad con la Constitución. 
gún la jurisprudencia del Consejo constitucional. No obstante, vio en esta constitucionalización, sin excesivo entusiasmo, un «efecto útil», en la medida en que, por una parte «la misma proporciona un fundamento incontestable a las medidas de policía administrativa tomadas por las autoridades civiles durante el estado de urgencia»y, por otro lado, «engloba la declaración y el desarrollo del estado de urgencia aportando precisiones de fondo y de procedimiento que hasta el momento se encontraban solamente en la ley ordinaria y que, por tanto, el legislador ordinario podía modificar», en particular en lo relativo a los motivos de declaración del estado de urgencia. En cambio, el texto aprobado por el Senado el 22 de marzo de 2016 se mostró, según el informe de la Comisión de leyes constitucionales del Senado, más preocupado por «fijar en la Constitución límites a la decisión de las autoridades civiles en cuanto a la aplicación del estado de urgencia, a fin de preservar las libertades y suprimir cualquier riesgo de extralimitación o de utilización desviada del estado de urgencia» ${ }^{31}$. De ahí la introducción de la mención al papel de la autoridad judicial, «guardiana de la libertad individual» (artículo 66 de la Constitución), el reforzamiento del control parlamentario y, sobre todo, la remisión a una ley orgánica de la tarea de determinar las condiciones de aplicación del estado de urgencia, como ya había sugerido el «Comité Balladur».

Pero la problemática de la constitucionalización del marco y del régimen jurídico del estado de urgencia también ha revelado una dificultad, consistente en las ambigüedades inherentes a la situación de excepción, en cuanto a su duración misma.

\section{La cuestión de la duración del estado de urgencia}

Este asunto es sin duda el que se muestra más problemático en torno a la cuestión de la situación de excepción en Derecho. En efecto, la naturaleza y la amplitud de la amenaza terrorista tienden a dilatar, de alguna manera, la situación de excepción. De hecho, ésta pierde su carácter excepcional, tal y como se entiende en un esquema clásico (situación normal/situación de excepción), para situarse en un estado de permanencia que no indica su nombre. Tiende, así, a fundirse jurídicamente con la normalidad, que queda de este modo fagocitada. Ante la necesidad de aportar una respuesta adaptada a una amenaza duradera, la situación de excepción y el estado de normalidad tienden a confundirse y dar origen a un tipo inédito de situación jurídica. Es lo que Davis Dyzenhaus denomina una «nueva normalidad», es decir «un estado de inseguridad» que se convierte en permanente y que requiere, en consecuencia, respuestas acordes: «pero

31 BAs, P.: Rapport fait au nom de la Commission des lois constitutionnelles, de législation, du suffrage universel, du Règlement et d'administration générale sur le projet de loi constitutionnelle, adopté par l'Assemblée nationale, de protection de la Nation, n. ${ }^{\circ} 447,9$ de marzo de 2016, p. 10. 
si estas respuestas persisten en un futuro indefinido, corremos el riesgo de deteriorar de forma permanente el Estado de Derecho y de contaminar el resto del orden jurídico» ${ }^{32}$. Lo que está en cuestión es, por tanto, el carácter por definición temporal de la situación de excepción frente a la «duración indefinida» de la amenaza. En este caso «le falta a la declaración del estado de excepción uno de sus trazos esenciales: la anticipación de su fin. Un estado de excepción permanente parece una contradicción en sus términos. Si las condiciones son tales que el orden político y jurídico debe ser reconfigurado indefinidamente, es éste la nueva normalidad, no el estado de excepción» ${ }^{33}$.

El Consejo de Estado, en su opinión citada anteriormente sobre el proyecto de ley constitucional «de protección de la nación», percibió bien este peligro y esta contradicción. Así, en cuanto a la prórroga del estado de urgencia por la ley más allá de 12 días, precisó: «siendo el estado de urgencia un «estado de crisis», estas renovaciones no deberían sucederse indefinidamente. Si la amenaza que está en el origen del estado de urgencia se convierte en permanente, habrá que acudir entonces a los instrumentos de lucha permanentes, dándoles, si es necesario, un fundamento constitucional duradero». Ésta es la razón por la cual se opone al sistema inicial del proyecto de ley constitucional, en la medida en que instauraba «un régimen que, sin ser el estado de urgencia, lo prolongaba temporalmente tomando de él ciertos rasgos». Se trataba, en efecto, de tomar en cuenta una situación de riesgo, posterior al fin del estado de urgencia, justificando las medidas adoptadas. El Consejo de Estado estimó, así, no sin un cierto apuro, que «en la hipótesis de la persistencia de un peligro inminente para el orden público, mientras no se hubieran reiterado los hechos constitutivos de atentados graves contra el orden público que hubiera al inicio de la declaración del estado de urgencia (...), el objetivo perseguido podría ser alcanzado simplemente por la adopción de una ley que prorrogase una vez más el estado de urgencia, adaptando las medidas susceptibles de ser tomadas a lo que exijan las circunstancias».

Por su parte, el Consejo constitucional, en su decisión n. ${ }^{\circ} 2015-527$ QPC de 22 de diciembre de 2015 (citada anteriormente), tampoco dejó de llamar la atención sobre la necesidad de circunscribir y de hacer proporcional la duración del estado de urgencia a las circunstancias que lo originen, tal y como se prevé en el artículo 1. ${ }^{\circ}$ de la ley de 1955: «considerando (...) que el estado de urgencia, declarado por decreto en Consejo de ministros, más allá de los doce días de duración, debe ser prorrogado por una ley en la cual se fije la duración; que esta duración no debe ser excesiva teniendo en cuenta el peligro inminente o la catástrofe pública que haya conducido a la declaración del estado de urgencia; que si el legislador prolonga el estado de urgencia por una nueva ley, las medidas de arresto domiciliario decretadas anteriormente no pueden ser prolongadas sin ser renova-

32 Art. cit., p. 747.

33 Dyzenhaus, D.: ibid, pp. 751-752.

UNED. Teoría y Realidad Constitucional, núm. 38, 2016, pp. 507-528 
das» (considerando 13). Sin embargo, el estado de urgencia inicialmente proclamado por el decreto n. ${ }^{\circ} 2015-1475$ de 14 de noviembre de 2015 en aplicación de la ley n. ${ }^{\circ}$ 55-385 de 3 de abril de 1955, la noche misma de los atentados de París, ya ha sido prolongado por las leyes de 20 de noviembre de 2015 , de 19 de febrero de 2016 y de 20 de mayo de 2016 hasta el 26 de julio de 2016, es decir, 8 meses después de los atentados de París, y por la ley n. ${ }^{\circ} 2016-987$ de 21 de julio por 6 meses más, tras el atentado de $\mathrm{Niza}^{34}$.

El proyecto de ley constitucional «de protección de la nación» pretendía eludir esta cuestión de la duración de estado de urgencia trasladando al legislador, más allá de los 12 días, las eventuales prórrogas del estado de urgencia, fijadas en 4 meses (reducidas a 3 meses por el Senado). Ha de señalarse que la ley de 1955 no imponía ninguna duración precisa en cuanto a la prórroga del estado de urgencia ${ }^{35}$. Sin embargo, habría podido adoptarse al respecto una solución análoga a la relativa a los poderes de crisis del artículo 16 de la Constitución. La ley constitucional de 23 de julio de 2008 vino precisamente a reforzar, en efecto, las garantías en cuanto a la duración de la aplicación del artículo 16. Un nuevo párrafo prevé una posible remisión al Consejo constitucional tras un periodo de treinta días, por parte de los presidentes de las asambleas parlamentarias, sesenta diputados o sesenta senadores; una auto-cuestión un mes después y, más allá, en cualquier momento, a fin de verificar si las condiciones iniciales se siguen produciendo. Si bien es cierto que la opinión del Consejo constitucional sólo vincula al jefe del Estado cuando se emite con ocasión de la aplicación del artículo 16, su publicidad y el tener como testigo a la opinión pública harían difícil que el Presidente de la República la ignorase.

Desde una perspectiva más amplia, parece que los poderes públicos finalmente han caído en la trampa de la «nueva normalidad» evocada por David Dyzenhaus. Así, el Parlamento aprobó el 25 de mayo de 2016 el proyecto de ley «por el que se refuerza la lucha contra el crimen organizado, el terrorismo y su financiación, y se mejora la eficacia de las garantías del proceso penal». Este texto comporta principalmente medidas que refuerzan de manera permanente los poderes de policía administrativa en el marco de la prevención de amenazas terroristas. Prevé además arrestos domiciliarios para las personas que retornen de Irak o de Siria y retenciones policiales para controles de identidad. En la medida en que esas disposiciones no figuraban hasta el momento más que en el marco del estado de urgencia, puede deducirse que este texto opera de alguna manera trasladando a la normalidad jurídica medidas que estaban reservadas a la situación de excepción.

Por otra parte, en su opinión de 28 de enero de 2016 sobre el proyecto de ley, el Consejo de Estado consideró que «las diferentes medidas previstas —arresto

34 Nuevos datos añadidos por la traductora.

35 «La ley que autoriza la prórroga más allá de doce días del estado de urgencia fija su duración definitiva».

UNED. Teoría y Realidad Constitucional, núm. 38, 2016, pp. 507-528 
domiciliario, obligar a la persona a presentarse periódicamente en los servicios de policía o de gendarmería, de declarar su domicilio y sus identificadores de medios de comunicación electrónica, de señalar sus desplazamientos, prohibición de ponerse en contacto con determinadas personas - eran de una naturaleza que permite alcanzar el objetivo de protección del orden público perseguido por el proyecto de ley», asegurando el carácter proporcionado del dispositivo en cuestión. Constató igualmente que el arresto domiciliario y sus medidas de acompañamiento «comportaban un grado de coerción significativamente inferior a las medidas previstas por el artículo 6 de la ley n. ${ }^{\circ} 55-385$ de 3 de abril de 1955 relativa al estado de urgencia».

Sin embargo, el estado de urgencia está en proceso de convertirse en un estado de necesidad, lo cual significa que la situación de excepción se hace permanente y da paso a un nuevo tipo de legalidad para todo tipo de problema en relación con los estándares del Estado de Derecho. En estas condiciones, la constitucionalización del estado de urgencia, que podía justificarse por el cuestionamiento de las libertades fundamentales que la misma comporta, dejaría de ser ejemplar y perdería su interés. El hecho es que asistimos así a la puesta en marcha de un estado de Derecho de necesidad edificado por el poder ejecutivo como respuesta a un nuevo tipo de amenaza y de peligro, y ello con el consentimiento del juez administrativo y constitucional y del legislador.

\section{LA CONSTITUCIONALIZACIÓN DE LA PRIVACIÓN DE LA NACIONALIDAD}

La segunda parte del proyecto gubernamental de ley constitucional «de protección de la nación», aprobado en Consejo de ministros el 23 de diciembre de 2015 , extendió la privación de la nacionalidad a los franceses de nacimiento que tengan además otra nacionalidad. Su artículo 2 disponía concretamente: «el artículo 34 de la Constitución ${ }^{36}$ se modifica de la siguiente manera: $1 .^{\circ}$ El tercer párrafo se reemplaza por las disposiciones siguientes: «la nacionalidad, incluidas las condiciones en las cuales una persona nacida francesa que posea además otra nacionalidad puede ser privada de la nacionalidad francesa si es condenada por un crimen que constituya un ataque grave contra la vida de la nación ${ }^{37}$ ». Una ley

$36 \mathrm{El}$ artículo 34 de la Constitución determina las competencias legislativas ordinarias. En particular, otorga competencia al legislador para «fijar las reglas» que conciernen a la nacionalidad. Ha de entenderse como tal las leyes que contienen una regulación detallada.

37 La noción de «ataque grave contra la vida de la nación» recuerda a la del artículo 15 de la Convención europea de derechos humanos, que permite a un Estado derogar algunas obligaciones de la Convención «en caso de guerra o de otro peligro público que amenace la vida de la nación». Según el TEDH, ha de entenderse por tal «una situación de crisis o de peligro excepcional e inminente que afecte al conjunto de la población y constituya una amenaza para la vida organizada de la comunidad que compone el Estado» (1 de julio de 1961, Lawless c./Irlanda, n. ${ }^{\circ}$ 332/57). 
ordinaria debía entonces intervenir para definir la lista de crímenes afectados por la privación de la nacionalidad y el procedimiento aplicable. Por «francés de nacimiento» se entendería una persona que dispone de la nacionalidad francesa desde su nacimiento, sea por filiación, sea en virtud del doble derecho de suelo (double droit du sol) $)^{38}$.

Esta disposición ha suscitado dos tipos de cuestiones: la de la oportunidad de la constitucionalización de la privación de la nacionalidad, por una parte, y la de la igualdad de trato entre franceses de nacimiento con doble nacionalidad y los que sólo tienen una nacionalidad, por otra.

\section{La oportunidad de la constitucionalización de la privación de la nacionalidad}

En el estado actual del Derecho positivo, la privación de la nacionalidad francesa está prevista en los artículos 25 y 25-1 del Código civil. El artículo 25 autoriza al Gobierno a declarar, por decreto emitido tras opinión conforme del Consejo de Estado, la pérdida de la nacionalidad francesa de las personas que la hubieran obtenido por adquisición (acquisition) y que dispongan además de otra nacionalidad. Entre los motivos susceptibles de producir esta privación de la nacionalidad, figura el de la condena por un crimen (crime) o un delito (délit) que constituya un acto de terrorismo o un atentado contra los intereses fundamentales de la nación. De este modo, se pone de manifiesto que tal privación no puede tener como efecto convertir a la persona de que se trate en apátrida ${ }^{39}$. En cuanto al artículo 25-1, el mismo precisa que los hechos susceptibles de conllevar la privación de la nacionalidad deben haberse producido con anterioridad a la adquisición de la nacionalidad francesa o en un periodo de diez años posterior a la misma, elevado a 15 años en caso de condena por terrorismo. En cualquier caso, no puede declararse más de 10 años después de los hechos.

Aparecida en el contexto de la Primera Guerra mundial, la privación de la nacionalidad francesa procede de una desconfianza hacia los naturalizados franceses sospechosos de falta de lealtad hacia Francia ${ }^{40}$. Esta sospecha fue perpetuada y ampliada por una ley de 10 de agosto de 1927, que extiende el campo de aplicación de la privación de la nacionalidad al conjunto de franceses por adquisición, y no sólo, como anteriormente, a los franceses naturalizados. Posteriormente, una

38 El «doble derecho de suelo» se refiere a la adquisición de la nacionalidad francesa por la persona nacida en Francia cuando al menos uno de sus progenitores también nació en Francia, como dispone el artículo 19-3 del Código civil francés (nota de la traductora).

39 Esta prohibición fue incluida en el artículo 25 del Código civil por la ley n. ${ }^{\circ}$ 98-170 de 16 de marzo de 1998. Anteriormente, la ley n. ${ }^{\circ}$ 96-647 había añadido a los motivos de privación de la nacionalidad del artículo 25 la comisión de un crimen o un delito que constituya un acto de terrorismo.

40 Leyes de 7 de abril de 1915 y de 10 de junio de 1917. 
serie de textos de 1934 a 1940 se encargó de limitar los derechos de los franceses naturalizados e instaurar un control del Gobierno sobre todas las situaciones que permitían adquirir la nacionalidad. El régimen de Vichy (1940-1944) instrumentalizó esta reglamentación contra los resistentes a la ocupación nazi y los judíos. Una ley de 16 de julio de 1940 relativa al procedimiento de privación de la condición de francés suprimió todo requisito temporal para declarar la privación y procedió a la privación de oficio de todo francés, de nacimiento o de adquisición, que hubiera salido del territorio nacional entre el 10 de mayo y el 30 de junio de 1940 a fin de viajar al extranjero sin motivo legítimo. Una comisión de estudio de la privación de la nacionalidad declaró la privación de 15.154 refugiados, de los cuales 6.307 eran judíos ${ }^{41}$. Este dispositivo y sus medidas fueron derogados tras la Liberación, antes de que la Orden de 19 de octubre de 1945 aprobase por primera vez en Francia un código de la nacionalidad y restableciera el Derecho sobre la privación anterior a la Segunda Guerra mundial, mediando algunas modificaciones. Este código de la nacionalidad se reintegró en 1993 en el Código civil.

En realidad, la extensión de la privación de la nacionalidad francesa a los franceses de nacimiento titulares de otra nacionalidad, deseada por el presidente de la República según manifestó en su discurso ante el Parlamento reunido en sesión conjunta el 16 de noviembre de 2015, podría haber tomado la vía de una simple adición al artículo 25 del Código civil. Ésta era la posición del antiguo ministro de Justicia y antiguo presidente del Consejo constitucional Robert Badinter, expuesta en un artículo publicado en el diario Le Monde, el 5 de febrero de 2016, según la cual no era necesaria una revisión constitucional. En la medida en que el primer párrafo del artículo 25 del Código civil dispone: «el individuo que ha adquirido la condición de francés puede, por decreto emitido tras opinión conforme del Consejo de Estado, ser privado de la nacionalidad francesa, salvo si la privación tiene como resultado convertirlo en apátrida», le bastaría al Parlamento, según Robert Badinter, reemplazar la referencia a aquel «que ha adquirido la condición de francés» por la expresión «todo francés». Además, una toma de posición a priori del Consejo constitucional habría permitido levantar la hipótesis de la eventual inconstitucionalidad de la extensión de la privación de la nacionalidad a los franceses de nacimiento con doble nacionalidad. No obstante, se ponía de manifiesto que, siempre según Robert Badinter, «la doble nacionalidad, considerada como una ventaja por gran parte de sus titulares, se convertiría, así, en una fuente de discriminación negativa». En efecto, los franceses con una sola nacionalidad, la francesa, no podrían ser privados de la misma, salvo que sean convertidos en apátridas, lo cual prohíbe el derecho a la nacionalidad francés.

41 BAs, P.: Rapport fait au nom de la Commission des lois constitutionnelles, de législation, du suffrage universel, du Règlement et d'administration générale sur le projet de loi constitutionnelle, adopté par l'Assemblée nationale, de protection de la Nation, Sénat, n. ${ }^{\circ} 447,9$ de marzo de 2016.

UNED. Teoría y Realidad Constitucional, núm. 38, 2016, pp. 507-528 
Por su parte, el Consejo constitucional tuvo ocasión de pronunciarse en dos ocasiones sobre la constitucionalidad de las normas relativas a la privación de la nacionalidad. Se trató en primer lugar, en 1996, de la ley tendente a reforzar la represión del terrorismo y de los atentados contra personas depositarias de la autoridad pública o encargadas de una misión de servicio público e incluyendo disposiciones relativas a la policía judicial. Este texto añadía a las causas de pérdida de la nacionalidad, las condenas por crimen o delito terrorista, añadido que se incluyó en el artículo 25 del Código civil. En su decisión n. ${ }^{\circ}$ 96-337 DC de 16 de julio de 1996, el Consejo constitucional estimó que, en virtud del derecho a la nacionalidad, los franceses de nacimiento y los franceses de adquisición están en la misma situación pero «que, sin embargo, el legislador ha podido, habida cuenta del objetivo tendente a reforzar la lucha contra el terrorismo, prever la posibilidad de que, durante un periodo limitado, la autoridad administrativa prive de la nacionalidad francesa a aquéllos que la han adquirido, sin que la diferencia de trato que de ello resulta viole el principio de igualdad; que, además, vista la particular gravedad que revisten por su naturaleza los actos de terrorismo, esta sanción ha podido preverse sin vulnerar las exigencias del artículo 8 de la Declaración de los Derechos del Hombre y del Ciudadano» ${ }^{42}$ (considerando 23). A este respecto, el Consejo constitucional hizo aplicación de su jurisprudencia tradicional en virtud de la cual el principio de igualdad no se opone a que las diferencias de situación puedan ser objeto de un trato diferente por un motivo de interés general, «siempre y cuando (...) la diferencia de trato que de ello resulta esté vinculada con el objeto de la ley que la establece» (considerando 22). Por lo tanto, no se excluía que esta jurisprudencia pudiera también aplicarse a la diferencia entre franceses con doble nacionalidad y franceses con sólo una nacionalidad, resultante de la extensión de la privación de la nacionalidad a los franceses de nacimiento, diferencia justificada por la prevención del riesgo de apatridia. Posteriormente, esta jurisprudencia fue confirmada en 2015: se planteó al Consejo constitucional una cuestión prioritaria de constitucionalidad con ocasión de la impugnación ante el Consejo de Estado de un decreto de privación de nacionalidad. En su decisión n. ${ }^{\circ} 2014-439$ QPC de 23 de enero de 2015, M. Abmed S., el Consejo constitucional se refirió a su decisión de 16 de julio de 1996. También recordó que la privación de la nacionalidad que sigue a una condena por terrorismo no puede conducir a convertir en apátrida a la persona de que se trate.

Sin embargo, el Consejo de Estado, en su opinión de 11 de diciembre de 2015 sobre el proyecto de ley constitucional «de protección de la nación», previamente a su aprobación por el Consejo de ministros, estimó que la extensión de la pérdida de la nacionalidad a los franceses con doble nacionalidad de nacimiento condenados por hechos de terrorismo presentaba un riesgo de inconstituciona-

42 «La ley sólo debe establecer penas estricta y evidentemente necesarias, y tan sólo se puede ser castigado en virtud de una ley establecida y promulgada con anterioridad al delito, y aplicada legalmente». 
lidad, justificando por ello su inclusión en la Constitución. Sin embargo, ese riesgo no proviene de un desconocimiento del principio de igualdad, en la medida en que existe una diferencia de situación, en cuanto al riesgo de apatridia, entre franceses con doble nacionalidad y con una. En este ámbito, la citada jurisprudencia del Consejo constitucional sería, por tanto, susceptible de aplicarse. En consecuencia, según el Consejo de Estado: "por lo tanto, extendiendo a las personas nacidas francesas la sanción de la privación ya autorizada por el Código civil para las personas devenidas francesas por adquisición, la disposición en cuestión no crea una ruptura de la igualdad entre estas dos categorías de personas». Es por ello que no se puede encontrar un riesgo de inconstitucionalidad. El Consejo de Estado estimó también que esta medida podría chocar con un eventual «principio fundamental reconocido por las leyes de la República» ${ }^{43}$, «que prohíba privar a los franceses de nacimiento de su nacionalidad». Pero además sería necesario que se probase la existencia de tal «principio fundamental reconocido por las leyes de la República», lo cual no es el caso por el momento.

El Consejo de Estado planteó en particular la cuestión de la conformidad de la medida gubernamental en relación con el principio de la garantía de los derechos en el sentido del artículo 16 de la Declaración de los Derechos del Hombre y del Ciudadano ${ }^{44}$. Para ello, en primer lugar situó el derecho a la nacionalidad en el marco de los derechos de la persona, más que como prerrogativa regia del Estado soberano: «la nacionalidad francesa representa desde el nacimiento un elemento constitutivo de la persona. Confiere a su titular derechos fundamentales cuya privación por el legislador ordinario podría calificarse de atentado excesivo y desproporcionado contra esos derechos».

Además, esta posición es también la de las jurisdicciones europeas. Si bien la Convención europea de derechos humanos no impide la privación de la nacionalidad, el Tribunal de Estrasburgo acepta conocer indirectamente asuntos relativos a la nacionalidad siempre que esté afectada directamente la salvaguardia de derechos en aplicación de la Convención, como por ejemplo el derecho a una vida familiar normal ${ }^{45}$, o el derecho a no ser sometido a tratos inhumanos o degradantes $^{46}$.

43 La noción de «principio fundamental reconocido por las leyes de la República» se evoca, sin más precisión, por el Preámbulo de la Constitución de 1946, que tiene en sí mismo valor constitucional. Dicha noción se retomó por el Consejo constitucional en su célebre decisión n. ${ }^{\circ}$ 71-44 DC de 16 de julio de 1971. La fuente de los «principios fundamentales reconocidos por las leyes de la República» se encuentra, esencialmente, en los grandes textos legislativos de la III República (1875-1940), según la jurisprudencia del Consejo constitucional. Pero éste se muestra a la vez muy prudente y moderado en cuanto al reconocimiento de estos «principios fundamentales reconocidos por las leyes de la República», a fin de no ser sospechoso de desarrollar un poder normativo excediendo las competencias que la Constitución le atribuye.

44 «Toda sociedad en la cual no esté establecida la garantía de los derechos, ni determinada la separación de los poderes, carece de Constitución».

45 STEDH de 11 de octubre de 2011, Genovese c./Malta, n. ${ }^{\circ}$ 53124/09.

46 STEDH de 3 de diciembre de 2009, Daoudi c./Francia, n. ${ }^{\circ} 19576 / 08$. 
Por su parte, el Tribunal de Justicia de la Unión Europea adopta una deriva similar, aunque el derecho a la nacionalidad no entre en las atribuciones de la Unión. En efecto, aborda indirectamente el derecho a la nacionalidad desde el punto de vista de la ciudadanía de la Unión. Así, en la medida en que la privación de la nacionalidad de un Estado miembro, a la cual no se opone el Derecho de la Unión, conlleva ipso facto la pérdida de la condición de ciudadano de la Unión, aquélla debe respetar el Derecho de la Unión, en particular el principio de proporcionalidad ${ }^{47}$. Por tanto, el Tribunal de Luxemburgo se ha fijado en las consecuencias producidas por esta privación de la nacionalidad de un Estado miembro sobre los derechos de la persona: «al examinar una decisión por la que se revoca la naturalización es preciso tomar en consideración las eventuales consecuencias que esta decisión acarrea para el interesado y, en su caso, para los miembros de su familia en lo que atañe a la pérdida de los derechos de que goza todo ciudadano de la Unión» ${ }^{48}$.

Así entendidas, la opinión del Consejo de Estado y las jurisprudencias europeas tienden a entender el derecho a la nacionalidad como un derecho humano. Sin embargo, existe ahí una confusión, que puso en evidencia el filósofo Yves Charles Zarka en un artículo publicado en el diario Le Monde el 7 de enero de 2016. En efecto, conviene distinguir, por un lado, los derechos humanos en tanto que derechos naturales: «no son atribuidos por nadie ni pueden ser retirados por nadie. Están ligados a la persona humana en tanto que tal y son inseparables de ella». Y por otra parte, el derecho a la nacionalidad, de naturaleza histórica y política: «la nacionalidad es siempre histórica, es decir, adquirida. Se confiere en virtud de la pertenencia a una nación, según las modalidades directas, éstas también históricas». Hay que añadir que las naciones son ellas mismas construcciones históricas, no realidades naturales. Si bien es legítimo que el Derecho internacional se ocupe de la cuestión de la apatridia ${ }^{49}$, ello no hace de la nacionalidad un derecho humano.

En cierta medida y si se hace abstracción de consideraciones políticas, es esta confusión la que estuvo en el origen de los desacuerdos entre la Asamblea nacional y el Senado cuando se examinó el proyecto de ley constitucional «de protección de la nación» y produjo finalmente su fracaso.

2. La cuestión de la igualdad de trato entre franceses con doble nacionalidad y con una

El texto de la revisión constitucional inicialmente propuesto al Parlamento por el Gobierno respondía a una doble preocupación, en resumen expuesta en el

47 STJUE de 2 de marzo de 2010, C 135/08, Janko Rottmann c./ Estado de Baviera, Rec. 20101 - 01449.

$48 \$ 56$ de la sentencia.

49 Es en este sentido en el que el artículo 15 de la Declaración universal de las Naciones Unidas, que no tiene en sí mismo valor normativo, precisa: «1. Todo individuo tiene derecho a una nacionalidad. 2 . Nadie puede ser arbitrariamente privado de su nacionalidad, ni de su derecho a cambiar de nacionalidad». 
discurso del presidente de la República ante el Congreso, el 16 de noviembre de 2015: la primera relativa al riesgo de inconstitucionalidad, tal y como evocó el Consejo de Estado en su opinión (precitada) del 11 de diciembre de 2015, la segunda referida a la voluntad de prevenir el riesgo de apatridia a consecuencia de la extensión de la privación de la nacionalidad a los franceses de nacimiento.

Durante el examen del texto por la Comisión de leyes constitucionales de la Asamblea nacional, el debate se centró en la cuestión de la desigualdad de trato, en relación con la privación de la nacionalidad, entre los franceses titulares de otra nacionalidad y quienes no lo son. Así, los diputados criticaban la introducción de diferencias entre el nuevo régimen de pérdida de la nacionalidad de los franceses de nacimiento, basado en la Constitución, y el aplicable a los franceses por adquisición, basado en los artículos 25 y 25-1 del Código civil. En este sentido, se ponía de manifiesto que la gravedad de las infracciones susceptibles de conllevar la privación era más elevada cuando se trataba de franceses de nacimiento.

Por otra parte, los diputados se mostraron decididos a «endurecer» las condiciones mismas de la privación de la nacionalidad. Así, el Gobierno se vio obligado a modificar su texto inicial. De ahí resultó la supresión de la mención a «otra nacionalidad» para quien incurre en la privación de todos los derechos vinculados a la nacionalidad y, finalmente, la extensión a los delitos que constituyan un atentado grave contra la vida de la nación de los actos susceptibles de producir la privación. No obstante, en este último caso, el Consejo de Estado había subordinado su opinión favorable al proyecto de ley constitucional a la condición de «limitar el campo de las infracciones susceptibles de justificar la privación de la nacionalidad», precisando que las infracciones que no son de naturaleza criminal «no justificarían una sanción tan grave como la privación, la cual podría ser calificada como desproporcionada».

Por lo tanto, el texto aprobado en primera lectura por la Asamblea nacional, el 10 de febrero de 2016, difería sensiblemente del proyecto gubernamental. Se propuso añadir al artículo 34 de la Constitución un tercer párrafo redactado así: «la nacionalidad, incluidas las condiciones en las cuales una persona puede ser privada de la nacionalidad francesa o de los derechos vinculados a ésta si es condenada por un crimen o un delito que constituya un ataque grave contra la vida de la nación». De ahí resultaba un régimen jurídico de la privación de la nacionalidad común a los franceses de nacimiento y a los franceses por adquisición y la desaparición de toda referencia a la doble nacionalidad.

Pero esta nueva redacción del proyecto de revisión constitucional propuesta por el Gobierno conducía también a suprimir la garantía contra todo riesgo de apatridia, contrariamente a los compromisos contraídos por el presidente de la República en su discurso de 16 de noviembre de 2015, y también a las disposiciones del artículo 25 del Código civil, así como a los compromisos internacionales de Francia. Sobre esto último, la Comisión de leyes constitucionales de la Asamblea nacional señaló que la Convención sobre el estatuto de los apátridas de 28 de septiembre de 1954, ratificada por Francia el 8 de marzo de 1960, no pro- 
híbe crear casos de apatridia ni expulsar apátridas: «la misma se dirige a dar un estatuto a los apátridas que no tengan la condición de refugiado ${ }^{50}$. Por otro lado, la Comisión señaló que Francia no estaba jurídicamente vinculada ni por la Convención para reducir los casos de apatridia de 30 de agosto de 1961, ni por la Convención del Consejo de Europa de 6 de noviembre de 1997, textos que ha firmado pero no ratificado. Por lo demás, estos textos no prohíben toda privación o pérdida de nacionalidad, especialmente en caso de «comportamiento que conlleve un perjuicio grave a los intereses esenciales del Estado parte» ${ }^{51}$, salvo, no obstante, que la persona de que se trate se convierta en apátrida. En todo caso, esta interpretación a minima de las obligaciones internacionales de Francia es, en parte, lo que pudo explicar que la Asamblea nacional pudiera hacer prevaler una situación de estricta igualdad entre franceses respecto a una eventual privación de nacionalidad, independientemente de que posean una o varias nacionalidades, bajo el riesgo de apatridia.

Sin embargo, el Senado, a la hora de analizar el proyecto de ley constitucional así aprobado por la Asamblea nacional, tomó el camino exactamente inverso. Si bien aceptó, a pesar de grandes cautelas, el principio de la revisión constitucional en nombre de la unidad nacional, también veló por proporcionarle unas ciertas garantías, de conformidad, además, con los principios expuestos por el presidente de la República ante el Congreso, a saber:

— subordinar la privación de la nacionalidad a la condición de que la persona de que se trate posea otra nacionalidad, lo cual viene a reintroducir la diferencia de trato entre franceses con doble nacionalidad y con una, lo sean de nacimiento o de adquisición;

- limitar la privación de la nacionalidad solamente a los crímenes que constituyan un atentado grave contra la vida de la nación;

- precisar el procedimiento seguido para declarar la privación, a saber: por decreto del Gobierno emitido tras opinión conforme del Consejo de Estado.

Así, el Senado aprobó, el 22 de marzo de 2016, la versión siguiente, bajo la forma de un tercer párrafo añadido al artículo 34 de la Constitución: «la nacionalidad, cuya privación, declarada por decreto emitido con opinión conforme del Consejo de Estado, solamente puede afectar a una persona condenada de forma definitiva por un crimen que constituya un atentado grave contra la vida de la nación y que disponga de otra nacionalidad además de la francesa».

50 Raimbourg, D.: Rapport fait au nom de la Commission des lois constitutionnelles, de la législation et de l'administration générale de la République sur le projet de loi constitutionnelle de protection de la nation, Assemblée nationale, n. ${ }^{\circ} 3451,28$ de enero de 2016.

51 Artículo 7 del Convenio Europeo sobre Nacionalidad hecho en Estrasburgo el 6 de noviembre de 1997. 
Como bien expuso la Comisión de leyes constitucionales del Senado, esta divergencia entre las opiniones de la Asamblea nacional y el Senado se basaba en un problema de fondo, en la medida en que «no es posible tratar de la misma manera a los titulares de una sola nacionalidad y al resto si se desea, al mismo tiempo, evitar el riesgo de apatridia. Lo uno es excluyente de lo otro» ${ }^{52}$. En consecuencia, mientras que la Asamblea nacional se decidió en favor de una estricta igualdad de trato entre franceses en cuanto a una eventual privación de la nacionalidad, a riesgo de asumir el riesgo de apatridia, el Senado optó por la consagración de la prohibición de crear apátridas, a riesgo de crear una diferencia entre la situación de los franceses con una sola nacionalidad y los de doble. Así entendida, la oposición entre las dos asambleas era irreconciliable. Ello manifestaba también una concepción diferente de la nacionalidad: concebida por la Asamblea nacional más como la capacidad discrecional del Estado soberano para determinar la pertenencia a la nación, mientras que el Senado se mostraba más preocupado por los derechos de la persona ligados a la nacionalidad. Es esta oposición la que condujo al jefe del Estado a renunciar a la totalidad de esta revisión constitucional en un breve comunicado, el 30 de marzo de 2016.

Por supuesto, el fracaso de la revisión constitucional se debió también a cálculos políticos, aunque la discrepancia introducida por la perspectiva de una privación de la nacionalidad de los franceses de nacimiento pudo trascender las líneas políticas de sus defensores. Finalmente se ha puesto de manifiesto, una vez asentada en parte la conmoción producida por los atentados de París, que el Parlamento, él mismo muy dividido, no deseaba realmente esta revisión constitucional. Por lo demás, y tratándose de la privación de la nacionalidad, la medida parecía más simbólica que provista de una eficacia práctica: desde 1973, se han declarado 13 privaciones por acto de terrorismo o atentado contra los intereses fundamentales de la nación. Desde una perspectiva general, esta revisión constitucional, como se ha podido verificar con la lectura de la prensa y de los debates en el Parlamento, más bien planteaba problemas en lugar de ser susceptible de responder eficazmente al riesgo terrorista en proceso de convertirse en permanente en el Estado de Derecho.

\footnotetext{
$* * *$

TitLe: The Failure of the Draft Constitutional Law «to Protect the Nation» in order to Include in the French Constitution the State of Urgency and Deprivation of Nationality

ABstRaCT: The draft Constitutional Law «to protect the nation» presented by the president of the Republic after the terrorist attacks in Paris on $13^{\text {th }}$ November 2015 had as an aim to include in the Constitution the notion of state of urgency and to extend deprivation of nationality to French by birth. This two
}

52 BAs, P.: Rapport fait au nom de la Commission des lois constitutionnelles, de législation, du suffrage universel, du Règlement et d'administration générale sur le projet de loi constitutionnelle, adopté par l'Assemblée nationale, de protection de la Nation, cit., p. 95.

UNED. Teoría y Realidad Constitucional, núm. 38, 2016, pp. 507-528 
faces of the government draft were the origin of an intense political and constitutional debate. Firstly, this debate focused on the principle consisting on including in the Constitution the state of urgency, which is an exception state whose origin is in the $3^{\text {rd }}$ April 1955 Act. Moreover, the question of duration of the state of urgency was also discussed: does this exception state risk giving birth to a «state of necessity" that the terrorist threat tends to make permanent? The extension of deprivation of nationality to French by birth has also been highly discussed regarding the opportunity of its inclusion in the Constitution and its modalities. Particularly, both chambers of Parliament were not able to agree on the issue of statelessness. They have immersed themselves in a contradiction which, apart from political calculations, finally explains the failure of the draft constitutional law: was there need to make prevail a strict equality among French with an only nationality and those with several nationalities and assume the risk of statelessness, or was there need to prevent the risk of statelessness and treat them in a different way?

RESUMEN: El proyecto de ley constitucional «de protección de la nación» presentado por el presidente de la República tras los atentados terroristas de París del 13 de noviembre de 2015, tenía por objetivo introducir en la Constitución la noción de estado de urgencia y la extensión de la privación de la nacionalidad a los franceses de nacimiento. Estas dos vertientes del proyecto gubernamental dieron lugar a un intenso debate político y constitucional. Este debate se centró, en primer lugar, en el principio mismo de la constitucionalización del estado de urgencia, que es un estado de excepción cuyo origen se encuentra en la ley de 3 de abril de 1955. También se planteó la cuestión de la duración del estado de urgencia: ¿no existiría el riesgo de que ese estado de excepción diera lugar al nacimiento de un «estado de necesidad» que la amenaza terrorista tiende a hacer de abora en adelante permanente? La extensión de la privación de la nacionalidad a los franceses de nacimiento también se ha discutido, principalmente en lo relativo a la oportunidad de su constitucionalización y sus modalidades. En particular, las dos cámaras del Parlamento no consiguieron ponerse de acuerdo sobre la cuestión de la apatridia. Se enfrascaron en una contradicción que explica finalmente, aparte de los cálculos políticos, el fracaso del conjunto del proyecto de ley constitucional: ¿era necesario hacer prevaler, en relación a la privación de la nacionalidad, una estricta igualdad entre franceses que sólo tienen la nacionalidad francesa y aquéllos con varias nacionalidades, y asumir así el riesgo de la apatridia, o bien había que prevenir el riesgo de apatridia y tratarles asi de manera diferente?

KEY WORDS: state of urgency, deprivation of nationality, rule of Law, French Constitution.

Palabras Clave: estado de urgencia, privación de la nacionalidad, estado de Derecho, Constitución francesa.

FECHA DE RECEPCIÓN: 06.06.2016

FECHA DE ACEPTACIÓN: 27.07.2016 